\title{
Effects of Exercise Preconditioning on Neurotrophin-4 and Tropomyosin Receptor Kinase B Expression in the Hippocampal CA1 Region Following Transient Global Cerebral Ischemia/Reperfusion in Wistar Rats
}

\begin{abstract}
Mohtaram Yazdanian (MSc) Department of Physical Education and Sport Sciences, Islamic Azad University, Bojnourd Branch, Bojnord, Iran

Mahtab Moazami (PhD)

Associate Professor in Sport Physiology, Faculty of Sport Sciences, Ferdowsi University of Mashhad, Mashhad, Iran

Mohammad Shabani (PhD)

Associate Professor, Department of Sport Sciences, University of Bojnord, Bojnord, Iran

Sadegh Cheragh Birjandi (PhD) Assistant Professor, Department of Sport Science, Islamic Azad University, Bojnourd Branch, Bojnourd, Iran

Corresponding author: Mahtab Moazami
\end{abstract}

Tel: +98-9153156705

Email : mahtab.moazami@gmail.com

Address: Department, Exercise

Physiology, Physical Education and Sports Sciences, Ferdowsi

University of Mashhad, Mashhad, Iran

Received: 07 Feb 2019

Revised: 01 Apr 2019

Accepted: 06 Apr 2019

\section{(c) (i) (9)}

This work is licensed under a Creative Commons Attribution 4.0 License.

\section{ABSTRACT}

Background and Objectives: Cerebral ischemia causes irreversible structural and functional damage in certain areas of the brain, especially in the hippocampus. The aim of this study was to examine effects of exercise preconditioning on neuronal cell death and expression of neurotrophin-4 (NT-4) and tropomyosin receptor kinase B (TrkB) in the hippocampal CAl region following transient global cerebral ischemia/reperfusion in rat.

Methods: Twenty-one male Wistar rats (weighing 250-300 g) were randomly divided into three groups (control+healthy, control+ischemia and exercise+ischemia). The rats in the exercise group ran on a treadmill five sessions a week for eight weeks. Ischemia was induced by occlusion of both common carotid arteries for 45 minutes. Cresyl violet staining was performed to assess cell death, and real-time PCR was carried out to evaluate expression of NT-4 and TrkB.

Results: Cerebral ischemia was associated with significant neuronal death in the hippocampal CAl region $(\mathrm{P}<0.05)$. Exercise significantly decreased the ischemia-induced cell death $(\mathrm{P}<0.05)$. NT-4 expression was significantly lower in the control+ischemia group and in the exercise+ischemia group compared to the control+healthy group $(\mathrm{P}<0.05)$, but there was no significant difference between the control+ischemia group and the exercise+ischemia group in terms of NT-4 expression ( $\mathrm{P}>0.05)$. Noreover, TrkB expression did not differ significantly between the groups $(\mathrm{P}>0.05)$.

Conclusion: When used as a preconditioning stimulant before the induction of cerebral ischemia, exercise could have neuroprotective effects against cerebral ischemiainduced cell death, but it has no significant effect on NT-4 and TrkB expression.

Keywords: Exercise Preconditioning, Ischemia/Reperfusion, NT-4, TrkB, Cell death.

This paper should be cited as: Yazdanian M, Moazami M, Shabani M, Cheragh Birjandi S [Effects of Exercise Preconditioning on Neurotrophin-4 and Tropomyosin Receptor Kinase B Expression in the Hippocampal CA1 Region Following Transient Global Cerebral Ischemia/Reperfusion in Wistar Rats]. mljgoums. 2019; 13(6):23-28 


\section{INTRODUCTION}

Stroke is an acute neurological disorder caused by cerebrovascular occlusion resulting from embolism, thrombosis or bleeding and cerebral vascular spasm (1). Secondary damage after acute stages of injury, such as in the reperfusion phase, usually exacerbates initial injury. The combination of the two stages determines the severity and outcomes of ischemic brain injury (2). Therefore, finding strategies that can increase neuronal resistance to the ischemia-induced neurodegenerative damage is of upmost importance.

Neurotrophins are a family of proteins that play an important role in neural growth and differentiation (3). Neurotrophin-4 (NT-4) is an important member of this family, which serves as a nerve growth factor in the hippocampus and exerts specific, selective biological effects through interaction with its specific receptor, tropomyosin receptor kinase B (TrkB) (4). It has been shown that NT-4/5 treatment reduces infarct size in rats with middle cerebral artery occlusion (5). Exercise can protect the neurons against ischemia/reperfusion injury by reducing some risk factors. In addition, exercise preconditioning generates an endogenous neuroprotective effect that will promote neuron survival after ischemic injury $(6,7)$. Exercise preconditioning also improves the self-healing ability of the brain after ischemic injury through increased regulation of neurotrophic factors $(8,9)$. Overall, exercise preconditioning can potentially reduce the extent of initial damage and increase neuronal survival after ischemic injury. However, the precise role of physical exercise prior to cerebral ischemia is not well understood. As a result, the aim of this study was to evaluate effects of exercise preconditioning on NT-4 and $\operatorname{TrkB}$ expression in the hippocampus following cerebral ischemia reperfusion.

\section{MATERIALS AND METHODS}

Twenty-one male adult Wistar rats (weighing 250-300 g) were purchased from the Pasteur Institute of Iran, Amol Branch. The rats were kept in standard cages under controlled conditions (temperature of $22-24{ }^{\circ} \mathrm{C}$ and light/dark cycle of 12:12 hours) with free access to food and water. The rats were randomly divided into three groups: control $(n=7)$, ischemia $(n=7)$ and exercise $(n=7)$. This exercise and surgical procedures were performed from $20^{\text {th }}$ of September to $30^{\text {th }}$ of November 2018. The study received approval from the Ethics Committee of Semnan University of Medical Sciences (ethical code: IR.SEMNAN.REC.1397.057). Gene expression measurement experiments were performed at Pasargad Tissue and Gene Knowledge Laboratory in Tehran, Iran.

Before the induction of ischemia, the rats in the exercise group trained on a treadmill (10lane animal-specific treadmill) five days a week for eight weeks. Initially, the rats became acquainted with the treadmill for 1015 minutes at speed of $15 \mathrm{~m} / \mathrm{min}$ and zero incline. Two days later, the main exercise was performed five days a week at a speed of 18 $\mathrm{m} / \mathrm{min}$ for 20 minutes and zero incline. After one week, the duration and intensity of the exercise and the treadmill incline increased gradually, so that the rats ran on the treadmill for 50 minutes at $30 \mathrm{~m} / \mathrm{min}$ with $10^{\circ}$ incline in the eighth week (10).

To create transient cerebral ischemia (11), the rats were anesthetized via intraperitoneal injection of ketamine/xylazine $(40 \mathrm{mg} / \mathrm{kg}$ ). Then, both common carotid arteries were released from carotid plaque, after which the vagus nerve was carefully removed from the carotid artery. Then, both common carotid arteries were blocked for 45 minutes using surgical clamps. Afterwards, the blood flow was restored immediately by removing the clamps. Reperfusion blood flow in the carotid arteries was confirmed by observation. The rats' rectal temperature during the surgery was at $36.5 \pm 0.5^{\circ} \mathrm{C}$. After the surgery, the subjects were kept separately for four days with free access to food and water.

The rats were sacrificed 72 hours after the induction of ischemia. The brain tissue was immediately removed and placed in liquid nitrogen. Paraffin blocks were prepared from the tissues and coronal sections with a thickness of $7 \mu \mathrm{m}$ were prepared for staining using a microtome. Real-time PCR method was used in order to evaluate gene expression. The tissue samples were stored at $-80{ }^{\circ} \mathrm{C}$ until analyses.

Nissl staining is commonly used to identify the basic structure of healthy neurons from necrotic neurons in the brain and spinal cord tissue. The tissue sections 
(three sections per animal) were transferred on silanized slides. Then, they were stained with $0.1 \%$ cresyl violet acetate solution. The slides were dried and covered with Entellan. The image of sections was taken using a light microscope equipped with an AX-70 Olympus camera under 400x magnification. Subsequently, using ImageJ software, cell count was performed along a $400 \mu \mathrm{m}$ line drawn from the hippocampal CA1 region of rats. Irregular and dark cells with unknown nuclei and nucleoli were considered dead and were therefore counted.

About $50 \mathrm{mg}$ of hippocampal tissue were separately homogenized for the extraction of total RNA in QIAzol lysis reagent. In order to remove the protein components, the resulting product was centrifuged, mixed with chloroform (1:0.5 ratio) and stirred well for 15 seconds. After centrifugation, the mixture containing RNA were removed and mixed with isopropanol at a ratio of 1 to 0.5 , left at room temperature for 10 minutes, and then centrifuged at $12,000 \mathrm{~g}$ for $10 \mathrm{~min}$. Pellet containing RNA was dissolved in ethanol. RNA concentration was determined by measuring optical density at 260/280 $\mathrm{nm}$. Synthesis of cDNA was carried out using $1 \mu \mathrm{g}$ of RNA and random hexamer primers and reverse transcriptase.

To confirm gene expression studies, quantitative real-time PCR was carried out. For this purpose, RNA was extracted using Qiazol solution according to CinnaGen protocol. After treating the extracted RNA with DNase I (Fermentas) and determining RNA quality, a single-stranded cDNA was prepared using oligodt primers (MWGBiotech, Germany) and reverse transcriptase enzyme (Fermentas). For this purpose, PCR reactions were carried out with a PCR master mix (Applied Biosystems) and SYBER Green dye using the ABI Step One thermocycler (Applied Biosystems, Sequences Detection Systems, Focter City, CA) according to the manufacturer's protocol. In addition, GAPDH was used as the housekeeping gene. Table 1 shows the sequence of the primers used in the experiments.

Forty cycles of real-time PCR were performed at $94{ }^{\circ} \mathrm{C}$ for 20 seconds, $58-60{ }^{\circ} \mathrm{C}$ for 30 seconds and $72{ }^{\circ} \mathrm{C}$ for 30 seconds. The gene expression level was measured by the 2$\mathrm{CT} \Delta \Delta$ method. Gene expression ratios were evaluated by the threshold cycle comparative method using the following formula:

$$
\begin{gathered}
\mathrm{R}=2^{-(\Delta \Delta \mathrm{CT})} \\
\Delta \Delta \mathrm{CT}=\left(\mathrm{CT}_{\text {target }}-\mathrm{CT}_{\text {refence }}\right)_{\text {Time } \mathrm{X}} \\
-\left(\mathrm{CT}_{\text {target }}-\mathrm{CT}_{\text {refence }}\right)_{\text {Time } 0}
\end{gathered}
$$

Standard and specific curves of each gene were plotted using at least two logarithmic concentrations in dilution order. Target gene expression was normalized to the reference gene and the expression of the control group was considered as the calibrator.

$$
\begin{aligned}
\text { Ratio } & =\frac{\left(\mathrm{E}_{\text {target }}\right)^{\Delta \mathrm{CT} \text { target }}}{\left(\mathrm{E}_{\text {reference }}\right)^{\Delta \mathrm{CT} \text { reference }}} \\
& \left(\Delta \mathrm{Ct}_{\text {refrence }}\right. \\
& =\mathrm{Ct}_{\text {control }}-\mathrm{Ct}_{\text {treatment }} \Delta \Delta \mathrm{Ct}_{\text {target }} \\
& \left.=\mathrm{Ct}_{\text {control }}-\mathrm{Ct}_{\text {treatment }}\right)
\end{aligned}
$$

In the above formula, $\mathrm{E}$ represents efficacy and is obtained by using a standard curve for the gene.

The results were reported as mean and standard deviation. Kolmogorov-Smirnov test was used to evaluate the normality of data. One-way ANOVA was used to compare the differences between the groups. In case of significant differences, Bonferroni post hoc test was performed. All statistical analyses were performed in SPSS software (version 16) at significance level of 0.05 .

Table 1- Sequence of the primers used in this study

\begin{tabular}{cl}
\hline Genes & \multicolumn{1}{c}{ Primer sequence } \\
\hline \multirow{2}{*}{ NT-4 } & For: CCCTGCGTCAGTACTTCTTCGAGAC \\
& Rev: CTGGACGTCAGGCACGGCCTGTTC \\
\hline \multirow{2}{*}{ TrkB } & For: TTATGCTTGCTGGTCTTGGGCTTC \\
& Rev: TCTGGGTCAATGCTGTTAGGTTCC \\
\hline \multirow{2}{*}{ GAPDH } & For: TGAAGGTCGGAGTCAACGGATTTGGT \\
& Rev: CATGTGGGCCATGAGGTCCACCAC
\end{tabular}




\section{RESULTS}

Exercise preconditioning reduced ischemia/reperfusion-induced cell death in the hippocampal CA1 region. The results of the Nissl staining showed that cells in the hippocampal CA1 region of ischemic rats were irregular and dark, and their nuclei and nucleoli were undetectable (Figure 1).

Transient ischemia caused necrotic death in

the neurons of the hippocampus. Cell death rates were significantly higher in the control + ischemia group compared to the control + healthy $(\mathrm{P}<0.05)$.

The number of necrotic neurons among rats in the exercise + ischemia group was significantly reduced compared to the ischemia group $(\mathrm{P}<0.05)$ (Table 1).

Figure 1- Nissl staining of the hippocampal CA1 region. A) Control + Healthy group. B) Control + Ischemia group. C) Exercise + Ischemia group (400x magnification)

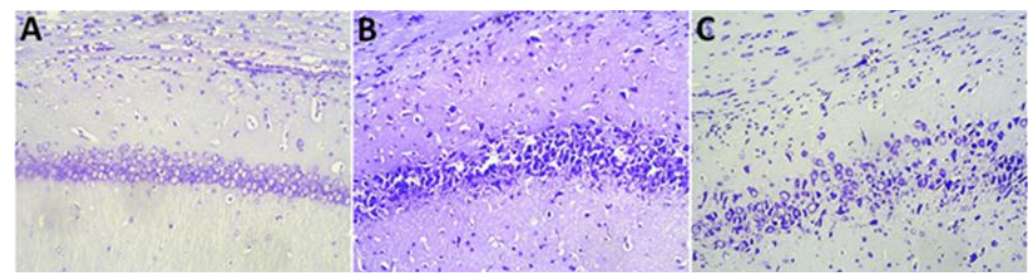

Table 1- Comparison of the mean percentage of necrotic cell death in the hippocampal CA1 region of rats in different groups. *: significant difference compared to control + healthy group; \#: significant difference compared to control + ischemia group

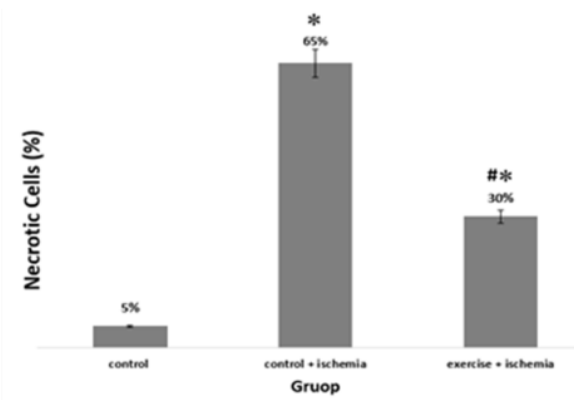

Figure 2- Effect of exercise preconditioning on NT-4 expression in different groups after induction of ischemia. *: significant difference compared with the healthy + control group $(\mathbf{P}<0.05)$

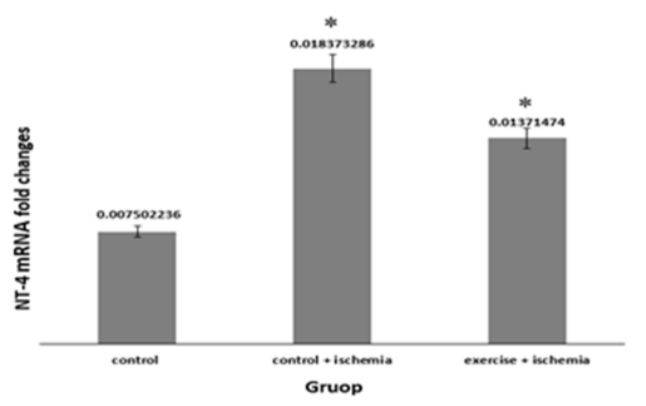

NT-4 expression was significantly lower in the control + ischemic and the exercise + ischemia groups than the control + healthy group $(\mathrm{P}<0.05)$, but there was no significant difference between the control
+ ischemia group and the exercise + ischemia group $(\mathrm{P}>0.05)$ (Figure 2). Moreover, TrkB expression did not differ significantly between the groups $(\mathrm{P}>0.05)$ (Figure 3).

Figure 3- Effect of exercise preconditioning on TrkB expression in different groups after induction of ischemia






\section{DISCUSSION}

Stroke is one the most common causes of death (11). As expected, our findings showed that ischemia increases neuronal cell death. This could be due to reduction of glutamate release and irritability. It has been demonstrated that the release of glutamate and overactivation of relevant receptors may be due to the cerebral ischemia-induced nerve damage, especially in the hippocampal neurons $(12,13)$. Inflammation also plays an important role in the pathogenesis of cerebral ischemia. Tumor necrosis factor- $\alpha$ is overexpressed as an inflammatory cytokine in certain conditions such as stroke and brain injury (14).

It is well-demonstrated that exercise has neuroprotective effects against ischemia/reperfusion injury. Exercise preconditioning also creates an endogenous neuroprotective effect that promote neuronal survival against ischemia-induced damage (6, 7). Jia et al. showed that pre-ischemic treadmill training could protect the splitting of striatal neurons in ischemic injury (15). Exercise before the induction of ischemia reduces cerebral damage against ischemia/reperfusion injury by preventing the release of glutamate (12). In addition, after exercise preconditioning, tumor necrosis factor- $\alpha$ can act as a neuroprotective factor and reduce ischemic injury (16).

The neuroprotective effects of exercise are also exerted through up-regulation of neurotrophin expression. This important regulatory protein increases neurogenesis and nerve regeneration by providing a broad neural network (17), which play a protective role against the damage caused by ischemia/reperfusion (18). Moreover, in a study conducted by Schäbitz et al., the endogenous neurotrophic values and therefore neuroprotection against ischemic injury were significantly higher in rats that had performed exercise preconditioning (19). Meanwhile, Oyesiku et al. indicated that an increase in NT$4 /$ TrkB expression might be involved in the modulation of neural response after brain injury (20). In addition, Chan et al. demonstrated that the increase in NT-4 expression ameliorates ischemic stroke damage (5). We assumed that exercise before the induction of ischemic stroke would change the expression of NT-4/TrkB. The results preconditioning did not have a positive impact on the NT-4 and TrkB expression, but it also reduced the expression of these genes compared to the control + healthy group. Exercise preconditioning also caused an increase in NT-4 and TrkB expression compared to the control + ischemia group, but this increase was not statistically significant. There are some uncertainties about the exact impact of exercise on brain injury. For example, it has been proposed that running on a treadmill can induce a chronic stress response that may have harmful effects in the event of a brain injury. Treadmill workout can cause stress and increase corticosterone level (21-23). Since hippocampus is an important target for stress hormones, it can have a negative effect on the hippocampus's plasticity (24). Therefore, the overall positive effect of forced treadmill exercise in experimental models could be affected by stress responses (23). On the other hand, it has been shown that induction of ischemia by common carotid artery occlusion can cause substantial damage in the hippocampal CA1 region. In this regard, $\mathrm{Li}$ et al. reported that a considerable damage in the hippocampal CA1 region after 3 minutes of common carotid artery occlusion (25). Another study also found that 5 minutes of occlusion would cause complete ischemia as well as neuronal death in the hippocampal CA1 region (26). However, the method of inducing ischemia in the mentioned study could be involved in reduction of gene expression in the exercise + ischemia group and the control + ischemia group compared to the healthy + control group. Further studies should be conducted to clarify the effects of exercise before induction of ischemia on the expression of neurotrophic factors.

\section{CONCLUSION}

Our findings suggest that pre-ischemia exercise could significantly reduce neuronal cell death in the hippocampal CA1 region. Remarkably, our results also indicated that exercise preconditioning can exert neuroprotective effects against ischemia, which provides a new perspective for finding an effective method to reduce the ischemiainduced cerebral damage. 


\section{ACKNOWLEDGEMENTS}

We would like to express our sincere appreciation to all people who helped us in this project and all members of the research team who worked on this

\section{REFERENCES}

1. Duncan PW, Sullivan KJ, Behrman AL, Azen SP, Wu SS, Nadeau SE, et al. Body-weight-supported treadmill rehabilitation after a stroke. New England Journal of Medicine. 2011; 364 (21): 2026-2036.

2. Stranahan AM, Zhou Y, Martin B, Maudsley S. Pharmacomimetics of exercise: novel approaches for hippocampally-targeted neuroprotective agents. Curr Med Chem. 2009; 16(35): 4668-78.

3. Deister C, Schmidt CE. Optimizing neurotrophic factor combinations for neurite outgrowth. J Neural Eng. 2006; 3(2): 172-9.

4. Persson H, Ibáñez CF. Role and expression of neurotrophins and the trk family of tyrosine kinase receptors in neural growth and rescue after injury. Curr Opin Neurol Neurosurg. 1993; 6(1): 11-8.

5. Chan KM, Lam DT, Pong K, Widmer HR, Hefti F. Neurotrophin-4/5 treatment reduces infarct size in rats with middle cerebral artery occlusion. Neurochemical Research. 1996; 21(7): 763-767.

6. Liebelt B, Papapetrou P, Ali A, Guo M, Ji X, Peng C, et al. Exercise preconditioning reduces neuronal apoptosis in stroke by up-regulating heat shock protein-70 (thermal shock protein-72) and extracellular-signal-regulated kinase 1/2. Neuroscience. 2010; 166(4): 1091-1100.

7. Zwagerman N, Plumlee C, Guthikonda M, Ding Y. Tolllike receptor-4 and cytokine cascade in stroke after exercise. Neurological research. 2010; 32(2): 123-126.

8. Kochanski R, Dornbos D, Ding Y. Neuroprotection and Physical Preconditioning: Exercise, Hypothermia, and Hyperthermia, in Innate Tolerance in CNS. Springer. 2013; 105-131.

9. Dornbos D, Ding Y. Mechanism of Neuroprotection Underlying Physical Exercise in Ischemia-Reperfusion Injury, in Brain Injury-Pathogenesis, Monitoring, Recovery and Management. InTech. 2012; DOI: 10.5772/32119.

10. Erfani S, Khaksari M, Oryan S, Shamsaei N, Aboutaleb $\mathrm{N}$, Nikbakht F. Nampt / PBEF / visfatin exerts neuroprotective effects against ischemia / reperfusion injury by modulating the Bax / Bcl-2 ratio and preventing caspase3 activation. J Mol Neurosci. 2015; 56(1): 237-43. doi: 10.1007/s12031-014-0486-1.

11. Bang OY. Multimodal MRI for ischemic stroke: from acute therapy to preventive strategies. J Clin Neurol. 2009; 5(3): 107-119.doi: 10.3988/jcn.2009.5.3.107.

12. Jia J, Hu YS, Wu Y, Yu HX, Liu G, Zhu DN, et al. Treadmill pre-training suppresses the release of glutamate resulting from cerebral ischemia in the rat. Exp Brain Res. 2010; 204(2): 173-9.

13. Moskowitz MA, Lo EH, Iadecola C. The science of stroke: mechanisms in the search of treatments. Neuron. 2010; 67(2): 181-98. doi: 10.1016/j.neuron.2010.07.002.

14. Sairanen TR, Lindsberg PJ, Brenner M, Carpén O, Sirén A. Differential cellular expression of tumor necrosis factoralpha and Type I tumor necrosis factor receptor after transient global forebrain ischemia. J Neurol Sci. 2001; 186(1-2): 87-99. project.

\section{CONFLICT OF INTEREST}

All authors declare that there is no conflict of interest.

15. Jia J, Hu YS, Wu Y, Liu G, Yu HX, Zheng QP, et al. Pre-ischemic treadmill training affects glutamate and gamma aminobutyric acid levels in the striatal dialysis of a rat model of cerebral ischemia. Life sciences. 2009; 84(1516): 505-511.

16. Wang X, Zhang M, Feng R, Li2, Ren W, Zhang F. Exercise Preconditioning, alleviating brain damage through excitatory amino acid transporter 2 and extracellular signalregulated kinase 1/2 after ischemic stroke in the rat. Mol Med Rep. 2015; 11(2): 1523-7.

17. Kuipers SD, Bramham CR. Brain-derived neurotrophic factor mechanisms and function in adult synaptic plasticity: new insights and implications for therapy. Curr Opin Drug Discov Devel. 2006; 9(5): 580-6.

18. Ding YH, Luan XD, Li J, Rafols JA, Guthinkonda M, Diaz FG, et al. Exercise-induced overexpression of angiogenic factors and reduction of ischemia / reperfusion injury in stroke. Current neurovascular research, 2004; 1(5): 411-420.

19. Schäbitz W, Steigleder T, Cooper-Kuhn CM, Schwab S, Sommer $\mathrm{C}$, et al. The intravenous brain-derived neurotrophic factor enhances post-trauma sensorimotor recovery and stimulates neurogenesis. Stroke. 2007; 38(7): 2165-2172.

20. Oyesiku NM1, Evans CO, Houston S, Darrell RS, Smith JS, Fulop ZL, et al. Regional changes in the expression of neurotrophic factors and their receptors following acute traumatic brain injury in the adult rat brain. Brain Research. 1999; 833(2): 161-172.

21. Leasure JL, Jones M. Forced and voluntary exercise differentially affect brain and behavior. Neuroscience. 2008; 156(3): 456-65. doi: 10.1016/j.neuroscience.2008.07.041.

22. Brown DA, Johnson MS, Armstrong CJ, Lynch JM, Caruso NM, Ehlers LB, et al. Short-term treadmill running in the rat: what kind of stressor is it? J Appl Physiol(1985). 2007; 103(6): 1979-85.

23. Svensson M, Rosval P, Boza-Serrano A, Andersson E, Lexel J, Deierborg T. Forced treadmill exercise can induce stress and increase neuronal damage in a mouse model of global cerebral ischemia. Neurobiology of stress. 2016; 5: 8-18.

24. McEwen BS. Stress and Hippocampal Plasticity. Anna Rev Neurosci. 1999; 22: 105-22.

25. Li XX, Nomura T, Aihara H, Nishizaki T. Adenosine enhances glial glutamate efflux via A2a adenosine receptors. Life sciences. 2001; 68(12): 1343-1350.

26. Williams-Karnesky RL, Stenzel-Poore MP. Adenosine and Stroke: maximizing the therapeutic potential of adenosine as a prophylactic and acute neuroprotectant. Curr Neuropharmacol. 2009; 7(3): 21727. doi: $10.2174 / 157015909789152209$ 